\section{A VIOLÊNCIA CONTRA A PESSOA IDOSA}

\section{ENTREVISTA ESPECIAL COM VICENTE DE PAULA FALEIROS}

Entrevistadora: Jacira do Nascimento Serra ${ }^{1}$ Realizada em outubro de 2014.

Em resposta ao honroso chamado que me foi feito para entrevistar um pesquisador que enriquecesse o volume 18, n.2 da Revista de Políticas Públicas (RPP) do Programa de Pós-Graduação em Políticas Públicas da Universidade Federal do Maranhão (PPGPP/UFMA), cujo Dossiê Temático é Poder, Violência e Políticas Públicas na Sociedade Contemporânea, e considerando minha área de pesquisa no campo da Violência contra a Pessoa Idosa, não tive dúvida em convidar um professor que, além de militante dos direitos humanos há diversos anos, vem fazendo amplo e sistemático trabalho de investigação nessa área - Prof. Dr. Vicente de Paula Faleiros. Pela sua militância na área, pelos trabalhos e livros publicados relacionados à temática, foi com muita satisfação que recebi seu aval para realizar a entrevista.

Vicente de Paula Faleiros é graduado em Direito pela Faculdade de Direito de Franca (1966) em Serviço Social pela Universidade de Ribeirão Preto (1966). Possui doutorado (PhD) pela Université de Montreal (1984) e pós-doutrados pela Escola de Altos Estudos em Ciências Sociais/Paris (EHESS) (1991) e Université de Montréal (1996). Especialista em Gerontologia pela Sociedade Brasileira de Geriatria e Gentologia (SBGG). Professor titular aposentado da Universidade de Brasília de onde é, atualmente Colaborador. É também professor da Universidade Católica de Brasília (UCB). Entre os temas de estudo e pesquisa tem privilegiado os seguintes: criança e adolescente, assistência social, saúde pública, previdência, regulação, teoria e metodologia do Serviço Social, velhice/gerontologia e violência. Integra o grupo de pesquisa do Conselho Nacional de Desenvolvimento Científico e Tecnológico (CNPq)
Geracionalidade, Imaginário e Violência (GEVIM). É professor emérito da Universidade de Brasília.

Da vasta obra de autoria do entrevistado, cabe destacar os livros: Estratégias em Serviço Social; Globalização, correlação de forças e serviço social; Saber profissional e poder institucional; A política social do estado capitalista; Metodologia e ideologia do trabalho social; Estratégias em Serviço Social; Globalização, correlação de forças e serviço social; Saber profissional e poder institucional; A política social do estado capitalista. Metodologia e ideologia do trabalho social; Fundamentos e políticas contra a exploração e abuso sexual de crianças e adolescentes; Crianças e Adolescentes-Pensar e Fazer; Violência contra a Pessoa Idosa: ocorrências, vítimas e agressores.

Entrevistadora - A violência contra a pessoa idosa é um fenômeno histórico, complexo, diversificado, polissêmico e controverso; não é um fenômeno novo, mas, como lembrei alhures "[...] o que é contemporâneo, é a sua demarcação como objeto de estudo, pois foi só a partir da década de 1990, que a violência deixou de ser vista como fenômeno exclusivo da segurança pública, passando a ser analisada por vários setores nacionais, e a ter repercussão nos órgãos internacionais." (SERRA, 2005, p. 1). Lembro ainda, que no Brasil, a discussão sobre as violências contra as pessoas idosas tomou impulso nas últimas duas décadas do século passado, tendo como um dos fatores 0 aumento crescente da população idosa e 0 interesse da comunidade acadêmica pela questão. Com efeito, na produção científica, foi se constituindo uma matriz de conhecimento centrada na violência contra as pessoas idosas sob múltiplos olhares investigativos. 0 Professor Faleiros há diversos anos vem fazendo um amplo e sistemático trabalho de pesquisa sobre a temática.

Vicente de Paula Faleiros - Obrigado pela referência. Não estudo políticas públicas como diletante, mas como militante dos direitos humanos. Os direitos humanos das pessoas idosas são 
socialmente invisíveis. Há uma negação da velhice por meio da discriminação e da naturalização do envelhecer, reduzido ao biológico, às perdas de funcionalidade ou de capacidade para atividades da vida diária. As escalas geriátricas e gerontológicas que medem a velhice têm como pressuposto o quanto se perdeu ao longo dos anos em várias dimensões, em geral fragmentadas: audição, visão, mobilidade, cognição, estado dos órgãos vitais. Assim, envelhecer é ser menos. Esta menorização e fragmentação dimensional da pessoa idosa é uma negação da cidadania, da sociedade para todas $\mathrm{e}$ de todas as idades. A idade é cronológica, social e individualmente vivida, culturalmente construída com seus processos de inclusão e exclusão. As pessoas idosas são sujeitos de direitos, agentes culturais e têm uma contribuição econômica, social e política significativa. Economicamente, não somente estão no trabalho, principalmente até os 70 anos, como ativam o consumo e a transferência de renda para outras gerações. Socialmente são produtivos na vida social e familiar e são atores políticos na intervenção nas organizações da sociedade e na re-invenção de relações. Pensar a velhice como cidadania, uma etapa de vida, uma relação multidimensional contribui para combater a violência.

Entrevistadora - A violência contra a pessoa idosa está situada no contexto estruturante de negação da vida e da destruição do poder. Como o senhor distingue atos de violência da estrutura da violência?

Vicente de Paula Faleiros - No meu livro Violência contra a Pessoa Idosa: Ocorrências, Vitimas e Agressores (Editora Universa, 2007) coloco a questão da violência não como ato individual ou grupal isolado e associado à vingança, à raiva, ao descontrole do agressor, mas como uma relação desigual de poder, estruturado cultural, social e economicamente que se exerce tanto na dinâmica da relação interpessoal como institucionalmente. Por exemplo, em artigo publicado na Revista Ser Social $n^{0} 2$, mostro a relação da violência intrafamiliar contra a pessoa idosa articulada ao desemprego, à dependência econômica do agressor, à convivência na mesma residência, ao uso de drogas lícitas e ilícitas e à trajetória de conflitos e relações da família em seu contexto de mudanças.

Entrevistadora - A questão da violência contra a pessoa idosa, diante do rápido envelhecimento populacional e da transição social das famílias brasileiras, está se tornando mais explícita na contemporaneidade. Como o senhor analisa e entende a problemática?

Vicente de Paula Faleiros - Há mobilização da sociedadecontraaviolênciaaosidosos, principalmente no contexto da defesa dos direitos humanos e levando em conta a atuação de organizações internacionais como a Organização Mundial da Saúde (OMS) e a Organização das Nações Unidas (ONU). Em 1997 foi fundado a International Network for The Prevention os Elder Abuse com patrocínio da ONU. Em 1982 houve uma Assembleia Internacional sobre 0 Envelhecimento, em Viena, que chamou a atenção dos países para a questão, o que foi reforçado em 2002, em Madrid, no Plano Internacional para o Envelhecimento. Em 1994 o Brasil promulga a Política Nacional do Idoso, e em 2003 o Estatuto do Idoso, com influência da mobilização Interna e mobilização internacional. O Serviço Social do Comércio (SESC), desde os anos 60 , chamava a atenção para o processo do envelhecimento ativo. A implementação dos Conselhos de Direitos da Pessoa idosa, já antes da lei de 1994, impulsiona a discussão sobre envelhecimento. Sugiro a leitura do último $\mathrm{n}^{\circ}$ da Revista Argumentum. A criação de mecanismos de denúncia foi fundamental para dar vazão à visibilidade das denúncias.

Entrevistadora - Quais as formas de violência mais encontradas nas suas pesquisas com 0 segmento idoso?

Vicente de Paula Faleiros - As manifestações da violência se colocam em diferentes relações de 
poder: a violência intrafamiliar se expressa contra a integridade física, contra a integridade psicológica, contra o direito à renda e às finanças e até mesmo em violação da sexualidade. Esta violação pode chegar a $8 \%$ das denúncias, dependendo da fonte. A física, a psicológica e a financeira giram em torno de 30\% das denúncias cada uma. Há também negligência e abandono. Os principais agressores são filhos, filhas (64\%) e netos (5 a 10\%). As principais vítimas da violência intrafamiliar são mulheres $(54 \%$ das vítimas). Homens são predominantemente vítimas de violência de furto e acidentes, além de agressões. A negligência afeta mais os idosos acima de 80 anos. A violência institucional está presente tanto na negação ou falta de acesso a serviços como no mau atendimento. A violência das condições de mobilidade e acessibilidade urbana tem provocado quedas e acidentes. A discriminação é disseminada na desvalorização da pessoa idosa e no desrespeito de sua aparência e de sua autonomia.

Entrevistadora - A violência contra a pessoa idosa se articula ao contexto social e político em que se produzem e reproduzem as relações de violência. $A$ violência intrafamiliar está na ponta do iceberg, pois a sua incidência não está retratada pelos números oficiais das delegacias e internações hospitalares. A que o senhor atribui esse fato?

Vicente de Paula Faleiros - Há articulação entre a estrutura e a manifestação da violência. A estrutura econômica da exploração se articula com a desigualdade da Previdência Social, dos benefícios sociais que são regressivos e não progressivos. As classes ricas (principalmente empresariais) recebem proporcionalmente mais benefícios do Estado em termos de incentivos, isenções, créditos, que os mais pobres, por ex do Banco Nacional do Desenvolvimento Econômico e Social (BNDES), dos estímulos fiscais e refis. Os mais pobres pagam pela Previdência Social. A violência intrafamiliar e interpessoal está vinculada às relações de poder das instituições na efetivação dos direitos e às complexas relações da vida familiar com o trabalho, a educação, os valores, a droga e à trajetória familiar. A família não é uma mônada e nem uma manada. Implica busca da sobrevivência, união, separação, conflitos, disputa de autoridade. A sobrevivência das famílias pobres é o trabalho duro que afeta a todos seus membros. 0 adultocentrismo e o machismo são estruturados socialmente, condicionando as relações familiares e domésticas e manifestações de violência.

Entrevistadora - 0 senhor considera que com as políticas voltadas para a população idosa no nosso país houve uma melhor visibilidade das questões relacionadas à violência?

Vicente de Paula Faleiros - A implantação dos dispositivos de denúncia como os disque, das delegacias do idoso, das promotorias e varas do idoso, dos Centro de Referência Especializado de Assistência Social (CREAS) e unidades do Sistema Único de Saúde (SUS) dão possibilidade e abertura (inclusive coragem) para denunciar. No entanto os mecanismos de combate à violência ainda estão frágeis. A punição do agressor é complicada, muitas vezes, para a própria pessoa idosa que não quer seu filho na cadeia e fere sua expectativa de reciprocidade. É fundamental que haja espaços de convivência onde as pessoas idosas possam falar do tema e espaços de mediação de conflitos familiares para mudança das relações que vão ser trabalhadas coletivamente. As organizações de pessoas idosas e de defesa de direitos podem contribuir na prevenção da violência, inclusive com articulação do poder das pessoas idosas. As experiências dos movimentos feministas podem contribuir para o combate à violência contra a pessoa idosa.

Entrevistadora - Quais as formas de enfrentamento, na contemporaneidade, das diversas formas de violência que atingem o cidadão idoso no nosso país?

Vicente de Paula Faleiros - Enfrentar a violência é uma questão que hoje perpassa a sociedade e as 
políticas públicas. Que segurança pública queremos? Parece-me fundamental o trabalho em rede, que tem um fluxo resolutivo a partir da denúncia, num sistema de garantia de direitos, como aponta o Sistema de Garantia dos Direitos da Criança e do Adolescente.No entanto, a educação para o respeito, em todos os níveis, é fundamental. $O$ respeito não significa reverência, mas reconhecimento de direitos num Estado de Direito. Assim, direitos e deveres são recíprocos. Se as crianças têm que respeitar os mais velhos, estes têm que respeitar as crianças. $O$ enfrentamento da violência tem que ser institucionalizado em políticas integradas em que a Polícia seja a primeira a agir com autoridade reconhecida e não como brucutus.

Entrevistadora - Como o senhor avalia o papel da sociedade organizada nos fóruns e nos conselhos na busca da efetivação dos direitos das pessoas idosas?

Vicente de Paula Faleiros - A sociedade organizadaé mediação da educação e da pressão. Aaprendizagem da convivência e da mutualidade e a luta por direitos contribuem para a crítica à negação dos direitos na estrutura capitalista e nas relações interpessoais. É o educador coletivo, que precisa ter correspondência na organização do Estado, como nos Conselhos de Direitos e instituições públicas.

Entrevistadora - Nesse quadro, quais os avanços e retrocesso que o senhor destaca em relação aos direitos da pessoa idosa na contemporaneidade no Brasil?

Vicente de Paula Faleiros - A legislação foi mudando, passando de uma visão filantrópica, asilar, para a garantia do seguro contributivo, que chamo de modelo securitário da velhice, para uma legislação da seguridade, hoje articulada às políticas de envelhecimento ativo. No artigo citado da Revista Argumentum trato dessa dinâmica. 0 chamado envelhecimento ativo surgiu diante do aumento da longevidade, da necessidade de se reduzir custos com a população envelhecente, mas também com a discussão da qualidade de vida na velhice. Os equipamentos urbanos e os equipamentos sociais e familiares precisam se adaptar a essa população para oportunizar suas capacidades e não domesticar ou culpabilizar a velhice por sua forma de viver.

Entrevistadora - Qual sua expectativa em relação ao enfrentamento da violência contra a pessoa idosa para a próxima década no Brasil?

Vicente de Paula Faleiros - Se as leis forem cumpridas e as instituições forem efetivas (com orçamento necessário) temos as condições para reduzir a violência, mas a educação das famílias e da sociedade para a convivência intergeracional de quatro ou mesmo de mais gerações é também condição que vai possibilitar a mudança de relações. As lutas para reduzir a exploração econômica e a dominação são fundamentais para a cidadania enquanto processo civilizatório.

\section{REFERÊNCIA}

SERRA, Jacira do Nascimento. As múltiplas faces da violência contra os idosos no Brasil: violência simbólica contra os idosos, forma sutil de constrangimento de cidadania. In: JORNADA INTERNACIONAL DE POLÍTICAS PÚBLICAS, 2., 2005, São Luís. Anais.. São Luís: PPGPP/UFMA, 2005.

NOTA

\footnotetext{
Possui graduação em Medicina pela Universidade Federal do Estado do Rio de Janeiro (1982), especialização em Geriatria e Gerontologia pela Pontifícia Universidade Católica do Rio Grande do Sul (1987) e mestrado em Políticas Públicas pela Universidade Federal do Maranhão (2005) .
} 